\title{
Online Collaborative Writing for ESL Learners Using Blogs and Feedback Checklists
}

\author{
Grami Mohammad A. Grami ${ }^{1}$ \\ ${ }^{1}$ Department of European Languages, King Abdulaziz University, Saudi Arabia \\ Correspondence: Grami Mohammad A. Grami, P. O. Box 80202, Jeddah, 21589, Saudi Arabia. E-mail: \\ algrami@hotmail.com
}

Received: June 2, 2012 Accepted: August 1, 2012 Online Published: August 16, 2012

doi:10.5539/elt.v5n10p43 URL: http://dx.doi.org/10.5539/elt.v5n10p43

\begin{abstract}
This paper reports on the experience of seven Saudi female ESL students who worked collaboratively in an interactive online writing environment over a period of four weeks. It chronicles their experiences with online writing tasks, documents their responses to online feedback, and examines their attempts to cope with different settings and audiences. It was found that interactive features of weblogs helped establish a valid peer review culture as an integral part of collaborative writing. The experience also helped develop critical thinking and ability to identify target audience. In general, students' attitudes were positive and participants exhibited a desire to incorporate similar tasks in upcoming ESL writing classes. It is therefore recommended that educational authorities and teachers should solicit online resources more often.
\end{abstract}

Keywords: weblogs, collaborative learning, ESL writing

\section{Introduction}

Technological advances in the field of education have experienced an unprecedented momentum in the last few years thanks in no small part to easy access to the Internet and commercially available educational software. There are no signs this trend is going to phase out anytime soon. If anything, it is more likely to increase in popularity as an increasing number of people in developing countries have access to affordable technology in all walks of life. There are several reasons for the prevalence of online educational schemes, an obvious of which is the expanding IT infrastructure in many emerging market countries where the Internet was until recently considered a luxury rather than a necessity. Internet access means that online interaction at its various shapes and guises is now a common feature of average students' daily lives in these less developed countries, and this in turn translates into the abundance of unorthodox and previously unknown sources of knowledge which, unlike traditional classes, are less bounded by time or location.

My focus in this project is on online blogging which has become a common feature of the Internet. Despite its popularity, many experts believe that blogging has not been fully utilized as a learning venue especially in countries like Saudi Arabia where using the internet is traditionally associated with entertainment and social activities rather than with business or education. In this project, the progress and attitudes of seven university-level female EFL students working to improve their EFL writing via weblogs were observed. The ability to work collaboratively, to write for an audience other than teachers, to critically judge the feedback received, to provide feedback, and ultimately to review own writing from a different perspective are areas where students' development was investigated.

Data collected while students were posting their blogs to be read and commented on by their colleagues. There were interviews designed primarily to investigate students' attitudes towards blogs as means of improving their EFL writing, addressing different readership, receiving corrective feedback from a previously unconventional source, and providing insights to others. There was also a reflective element toward the end of the experiment to give participants the chance to look back at their experience and to evaluate its impact on their collaborative learning skills, critical thinking and ability to address different audiences. Data was collected from participants using the interviews, the texts they have written and the checklist forms they provided to others.

\section{Literature Review}

\subsection{English Writing in ESL Contexts}

L2 writing in its own right is particularly challenging even for the more advanced learner. (Hinkel, 2004; and 
Leki \& Carson, 1997) When it comes to the Saudi context, however, a multitude of factors further complicate this task including outdated teaching methodologies and materials in public school, (Whitfield \& Pollard, 1998) writing and reading ethos among learners which are lagging behind that of most developed nations, (McKay, 1992) the status of English in the society, (Gray, 2000; and McKay 1992) and the lack of exposure to authentic English texts, (Syed, 2003) all contribute to the less than satisfactory levels of ESL writing of Saudi students.

Many teachers in Saudi Arabian public schools are focused on the grammar translation method which implicates teaching long lists of new words usually without meaningful contexts and grammatical rules. Some expatriate teachers such as McKay (1992) noted that many students were lazy and not as hard working as student from other countries. English in Saudi Arabia as Ghobain (2010) and Al Hazmi (2003) believe is as a foreign not a second language as in some other countries even if a growing number of the population realize its significance. Exposure to English for the average Saudi student is usually limited to language classes. The more privileged may go to English speaking countries on holidays or even study there but they are the exception rather than the norm.

The impact of these factors - and many others - is not hard to see. Year on year, English proficiency test results show that Saudi students have been among the lowest achieving in the world ever. In fact, only two neighboring countries fared worse in the IELTS writing test which in all intents and purposes is alarming news given that students from much less advantaged countries outperformed their Saudi counterparts and by a considerable margin in occasions. The available data does not show any real progress. If anything, the situation is getting worse rather than better making it natural to address the problem and its causes, and to conduct more research into its causes to be able to recommend solutions. (Ghobain \& Grami, 2012; and Grami \& Alkazemi, 2011)

Table 1. IELTS mean scores per country (Academic). From ESOL Research Notes, Issue 40, May 2010, University of Cambridge.

\begin{tabular}{llllll}
\hline Country & Listening & Reading & Writing & Speaking & Overall \\
\hline Nigeria & 6.11 & 6.07 & 6.21 & 7.06 & 6.42 \\
\hline Oman & 5.14 & 4.98 & 4.99 & 5.65 & 5.25 \\
\hline Pakistan & 6.00 & 5.62 & 5.69 & 6.04 & 5.90 \\
\hline Philippines & 7.05 & 6.60 & 6.21 & 6.81 & 6.73 \\
\hline Poland & 7.01 & 6.76 & 6.15 & 6.92 & 6.77 \\
\hline Qatar & 4.64 & 4.47 & 4.39 & 5.12 & 4.72 \\
\hline Russia & 6.64 & 6.61 & 5.95 & 6.61 & 6.51 \\
\hline Saudi Arabia & 4.97 & 4.79 & 4.69 & 5.67 & 5.10 \\
\hline Sri Lanka & 6.48 & 5.98 & 5.90 & 6.38 & 6.25 \\
\hline Taiwan & 5.78 & 5.81 & 5.32 & 5.73 & 5.72 \\
\hline Thailand & 5.96 & 5.87 & 5.34 & 5.72 & 5.78 \\
\hline Turkey & 6.00 & 5.85 & 5.46 & 5.96 & 5.88 \\
\hline United Arab Emirates & 4.86 & 4.69 & 4.69 & 5.36 & 4.97 \\
\hline Vietnam & 5.83 & 6.04 & 5.56 & 5.68 & 5.84 \\
\hline
\end{tabular}

* Countries in Italics are members of GCC council.

One possible solution is to provide more opportunities for corrective feedback from different sources. (Herrera, 2011; and Sheen, 2007) Another would be to encourage students to play a more active role in their own learning. (Singer et al., 2010) In theory, both solutions can be achieved via writing blogs which should be explained in the following sections.

\subsection{Blogging and Teaching ESL Writing}

There have been some genuine attempts to exploit the capabilities of the Internet in developing ESL writing mostly in large education institutions controlled and regulated by special IT departments. The system offers real opportunities for students to interact in a virtual classroom where they participate in conference-type classes, upload assignments, and even take quizzes, usually without worrying much about being physically present. Apparently, students can access these virtual classes from anywhere with an internet connection, effectively removing geographical boundaries. (Chang \& Kuo, 2011; Andergassen et al., 2009; Xie, 2005; and Lankshear \& Knobel, 2003) 
These are the systematic, institutional type of online projects we would like to see more in the future. However, despite being an enormous step forward, many of these classes are essentially following the plan or plans set by their respective instructors which given the practices of most writing teachers is very likely to remain teacher-centered and traditional.

There is nothing wrong with teacher-centered approaches themselves, not when most students are beginners and in need for constant guidance and monitoring. However, these approaches still lack an important aspect of modern ESL writing which is collaborative learning. (Brodahl, Hadjerrouit \& Hansen, 2011; Amir, Ismael \& Hussien, 2011; Elola \& Oskoz, 2010; Latif, 2008; Passig \& Schwartz, 2007; and Maimon, 1986) Maimon (ibid.) rightly observes that critical thinking remains an abstraction unless you engage in conversations with individuals of similar level of development. In other words, collaborative learning help develop critical thinking by means of stepping out of the self and into the audience. Collaborative learning therefore helps establish the concept of 'audience' or 'readership' usually not possible when students only write for their teachers as Amir, Ismael \& Hussien (2011) mention.

There should be more opportunities for students to take matters into their own hand with the guidance of a qualified teacher especially at earlier stages. Weblogs therefore correspond to this concern rather well in the sense that students do not write merely for grading purposes and are willing to decide on what course of action they should take not only in terms of topics but also on how to respond to feedback they receive. This type of critical thinking is usually missing from traditional classes where teachers are in control of most matters. (Andergassen et al., 2009; Tan, Mohamed \& Saw, 2009; Quitadamo \& Krutz, 2007, and Halvorsen, 2005) Andergassen et al. (2009) also believe that socializing is a very important driver to many students to engage in online blogging.

\section{Methodology}

In this section, I will discuss the methodological framework of the study, the process of selecting the participants, the design of the weblogs, and the timeline of the experiment. The study uses a combination of qualitative and quantitative methods to collect and analyze the data in the form of descriptive statistics from the written tasks and checklists, and more qualitative data from the interviews.

\subsection{Participants}

All participants are female Saudi ESL students in their tertiary education. They are all registered in a specialized forum for Saudi English majors where members share and discuss all subjects related to English language and academic life. Upon explaining the purpose of the study, they expressed their willingness to take part. As for their academic institutions, these students come from different arts and education colleges around the country. Five of the participants are in their first year in the university while the other two are in their second year. As none of the students has taken a proficiency English test (e.g. TOEFL or IELTS), it was difficult to determine their linguistic levels but we can theorize that as long as they were all English majors and must meet their respective schools' enrollment criteria, are competent English users.

The literature review shows that blogging is not an entirely new concept in EFL learning, and in the wider educational context as a whole (e.g. Tan, Mohamed \& Saw, 2009; and Xie, 2005). However, as it happened, none of the participants of this study has participated in any similar project or has been part of a class with comparable themes. They were in fact introduced to blogging for educational purposes for the first time as part of this study. This makes it interesting to observe how these students would fit in the new setting and how would they engage in activities with lots of potential and challenges ahead.

\subsection{Data Collection Techniques}

Four writing entries were required from each participant totaling 28 texts. Each week, participants were asked to write a topic of their choice that is a) recent and b) likely to be on interest to other participants and submit it online. The suggested length was about 250 words per text, or one page in MS Word. They then post their texts in their respective blogs where they will be viewed by their colleagues for open comments. I then randomly assigned two texts to every participant to provide her feedback using a simple checklist adopted from Alhazmi and Scholfield (2007) of the points she needed to discuss. In other words, each entry would have received comments from two reviewers.

There was confusion at the beginning of the experience as to the genres of writing expected. Some students enquired if their texts have to be scientifically rigorous others wanted to do more free writing. As there were no preset rules controlling the type contribution, the decision was left to students themselves. They wrote in a variety of topics ranging from politics, sport, fashion, and news headlines. 
The checklist contained both closed and open-ended items. The closed items were straightforward questions about the presence of a topic sentence, availability of supporting details (examples and explanations), the use of transition words, occurrence of grammatical or spelling mistakes, and an overall evaluation of the text (excellent, needs improvement or poor). The other part of the checklist required students to write their own evaluation of the text and any recommendation for improvement.

The use of the checklist when providing feedback to others was not meant to control students' response. It rather attempts to make the feedback received more consistent, detailed and meaningful.

Participants were phone interviewed individually shortly after the completion of the project. Questions ranged from the reasons of their participation to their insights of the experience. More bespoke questions relating to their choice of topics and response to feedback received from other participants were also included. All interviews were recorded and transcribed.

\section{Results and Discussion}

All students managed to write their respective blogs successfully and were able to provide their insights about their colleagues' texts using the checklist. In total, twenty-eights texts were published online and twice that number of feedback forms were received by the respective writers.

Statistically speaking, 28 texts were posted online averaging 4 per participant. The texts ranged between 149 and 326 word-long, or between 236-271 word-long texts on average. The following table shows the exact statistics on a weekly basis:

Table 2. Writing Tasks Statistics over the Period of the Experiment

\begin{tabular}{llllll}
\hline & & Writing task 1 & Writing task 2 & Writing task 3 & Writing task 4 \\
\hline $\mathrm{N}$ & Valid & 7 & 7 & 7 & 7 \\
\cline { 2 - 6 } & Missing & 0 & 0 & 0 & 0 \\
\hline Mean & 235.86 & 250.57 & 268.14 & 271.14 \\
\hline Std. Deviation & 62.358 & 31.128 & 45.470 & 43.299 \\
\hline Minimum & 149 & 203 & 176 & 201 \\
\hline Maximum & 342 & 301 & 305 & 326 \\
\hline
\end{tabular}

The texts were not extended pieces of writing. This however was ideal for the purpose of the study as students were expected to provide useful feedback to their peers on both local and global issues (i.e. grammar, spelling, punctuation, as well as logic and progression of ideas).

Being able to choose a topic rather than writing about a predetermined one should help students' critical thinking. This conclusion is not only supported by the literature (Andergassen et al., 2009; Quitadamo \& Krutz, 2007; and Halvorsen, 2005), but by students themselves who reported in the subsequent interviews that they have developed better judgment when selecting and writing about topics of their choice.

The interviews showed definite positive attitudes towards writing blogs and receiving feedback from peers. In fact, students' beliefs of collaborative writing and online means of communication along with feedback received from online peers were all very consistent. They reported a better-than-expected response from peers and they also were able to express their opinions freely about others' texts. One interviewee believes that responding to her peers' writings helped her develop her ability to judge her own writing, an interesting point that can be described as another advantage of peer feedback.

Identifying and addressing the audience accordingly is a skill that most writing tasks ignore as students usually consider the teacher to be their only audience. Writing for pleasure and to a different type of reader in a foreign language was a new experience to the participants of the study and they expressed their satisfaction with the experience.

Another extremely important skill students have developed is their critical thinking and ability to judge the feedback received from peers. Students during this experiment were aware that the feedback was provided by colleague students rather than more experienced instructors. This skill calls for good judgment on what points raised by colleagues are to be accepted and what others are to be scrutinized.

It must also be said that ESL writing is multifaceted and it is hard to say that one approach is suitable for all learners in all different situations. However, online blogging seems to address specific issues usually ignored in 
traditional ESL writing classes. Moreover, setting up a comprehensive online educational program normally calls for the resources of a large institution. In fact, the costs associated with buying, running and maintaining a similar program are usually beyond the reach of most schools and departments in Saudi Arabia.

In spite of that, this is not the end of the road because as we can see from this project, there are other cheaper alternatives that can be used in smaller settings. Students are willing to learn beyond the boundaries of the classroom and weblogs can be indeed a very useful alternative. The fact that students no longer write for instructors whose job eventually is to assess their work opens the door for new ways of thinking from students' perspective. Therefore, it would be advisable to encourage students to maintain online blogs as an extra-curriculum activity. These should be viewed by other students and, if possible, even readers from a much wider spectrum including students from other contexts.

\section{Conclusion}

Writing is the most challenging language skill and Saudi students are no exception to the rule. There are a multitude of factors that contribute to this, one of which is students' overdependence on teachers. Online blogging or weblogs however can play a role in balancing this by providing students with more opportunities for collaborative learning. In this project, students were able to explore new dimensions in their writing by playing different roles and interacting differently than they do in a typical classroom.

Online blogging was found to be an enriching experience and students were generally positive about it. Among many advantages of blogging, collaborative learning was really helpful in making students realize the complexity of various aspects of ESL writing. It also helps them develop audience awareness and identify audience categories other than the teacher.

As is the case with most small-scale studies, findings are not conclusive therefore they approached with an open mind. The results of the study however seemed congruent with previous research on technology and second language writing, so they should be viewed in their light as well. Blogging proved to be a valid and effective tool in second language writing as evidenced by the numerous benefits reported by students. These benefits in fact outweigh any drawbacks reported.

It must be acknowledged that the study at its current design is a systematic attempt to understand the way second language writing students deal with technology in the field of L2 writing and to establish a learning environment beyond the boundaries of traditional language classes. It also attempts to exploit potential benefits of IT advances and address challenges that may obstruct students' progress. The experiences of these genuine learners, their endeavours to learn how to write in an unconventional way, and their attempt to think out of the box are prime candidates for research topics. Furthermore, despite the shortcomings of access and breadth, it must also be noted that useful conclusions can be drawn.

\section{References}

Al-Hazmi, S. H. (2003). EFL Teacher Preparation Programs in Saudi Arabia: Trends and Challenges. TESOL Quarterly, 37(2), 341-344. http://dx.doi.org/10.2307/3588509

Amir, Z., Ismael, K., \& Hussin, S. (2011). Blogs in Language Learning: Maximizing Students' Collaborative Writing. Procedia: Social and Behavioral Sciences. 18, 537-548. http://dx.doi.org/10.1016/j.sbspro.2011.05.079.

Andergassen, M., Behringer, R., Finlay, J., Gorra, A., \& Moore, D. (2009). Weblogs in Higher Education - why do Students (not) Blog? Electronic Journal of e-Learning, 7(3), 203-215.

Brodahl, C., Hadjerrouit, S., \& Hansen, N. K. (2011). Collaborative Writing with Web 2.0 Technologies: Education Students' Perceptions. Journal of Information Technology Education: Innovations in Practice, $10,74-105$.

Chang, C. F., \& Kuo, C. H. (2011). A corpus-based approach to online materials development for writing research articles. English for Specific Purposes, 30, 222-234. http://dx.doi.org/10.1016/j.esp.2011.04.001

Elola, I., \& Oskoz, A. (2010). Collaborative Writing: Fostering Foreign Language and Writing Conventions Development. Language Learning and Technology, 14(3), 51-71.

ESOL Research Notes, Issue 40, May 2010, University of Cambridge.

Ghobain, E., \& Grami, G. (2012). English for Medical Students and the Myth of Native Models Superiority. ESP World, 35(12), 1-10.

Grami, G. M. A., \& Alkazemi, B. Y. (2011). Towards a framework for building a tool to assist L2 writing based 
on search engines capabilities: The Case of English Phrases and Collocations. The 3rd CSEDU, Noordwijkerhout, Netherlands. pp. 225-231.

Gray, J. (2000). The ELT Course Book as Cultural Artifact: How Teachers Censor and Adapt. ELT Journal, 45(3), 274-283. http://dx.doi.org/10.1093/elt/54.3.274

Halvorsen, A. (2005). Incorporating Critical Thinking Skills Development into ESL/EFL Courses. The Internet TESL Journal, 11(3).

Herrera, S. L. (2011). Exploring the Role of Corrective Feedback in Second Language Writing. MA Dissertation. The University of British Columbia.

Hinkel, E. (2004). Teaching Academic ESL Writing: Practical Techniques in Vocabulary and Grammar. Lawrence Erlbaum Associates. http://dx.doi.org/10.1017/ S0272263105240056

Lankshear, C., \& Knobel, M. (2003). Do-It-Yourself Broadcasting: Writing Weblogs in Knowledge Society. $84^{\text {th }}$ Annual Meeting of the American Educational Research Association. Chicago, Illinois.

Latif, M. M. A. (2008). A State-of-the-Art Review of the Real-Time Computer-Aided Study of the Writing Process. International Journal of English Studies, 8(1), 29-50.

Leki, I., \& Carson, J. (1997). "Completely Different Worlds": EAP and the Writing Experiences of ESL Students in University Courses. TESOL Quarterly, 31(1), 39-69. http://dx.doi.org/10.2307/3587974

Liou, H. C., \& Peng, Z. Y. (2009). Training Effects of Computer-Meditated Peer Review. System, 37, 524-525. http://dx.doi.org/10.1016/j.system.2009.01

McKay, S. L. (1992). Teaching English Overseas: An Introduction. Oxford: Oxford University Press.

Passig, D., \& Schwartz, G. (2007). Collaborative Writing: Online vs. Frontal. International Journal of E-Learning, 6(3), 395-412.

Quitadamo, I. J., \& Krutz, M. J. (2007). Learning to Improve: Using Writing to Increase Critical Thinking Performance in General Education Biology. Life Sciences Education, 6, 140-154. http://dx.doi.org/10.1187/cbe.06-11-0203

Sheen, Y. (2007). The effect of focused written corrective feedback and language aptitude on ESL learners' $\begin{array}{lllll}\text { acquisition } \quad \text { of } & \text { articles. }\end{array}$ http://dx.doi.org/10.1002/j.1545-7249.2007.tb00059.x

Singer, J., Togo, T., Mochiziku, S., \& Tanaka, M. (2010). Applying an autonomous learning approach to an English academic writing course. Ritsumeikan Studies In Language and Culture, 21(4), 209-219.

Tan, K. E., Mohamed, A. R., \& Saw, K. G. (2009). Improve School English in Malaysia through Participation in Online Threaded Discussion Group. Asian EFL Journal Quarterly, 11(2), 147-162.

Whitfield, B., \& Pollard, J. (1998). Awareness Raising in the Saudi Arabian Classroom. In Richards, J. C. (ed.), Teaching in Action. Alexandria: TESOL. pp. 143-149.

Xie, Y. (2005). Students' Lived Experience Of Using Weblogs In a Class: An Exploratory Study. Proceedings of the Annual Conference for the association of Educational Communications and Technology. pp. 839-846. 